\title{
Research Article \\ Exergy Analysis of Two Kinds of Solar-Driven Cogeneration Systems in Lhasa, Tibet, China
}

\author{
Haofei Zhang $\left(\mathbb{D}\right.$, Bo Lei $\mathbb{D}^{D}$, Tao Yu, and Zhida Zhao \\ School of Mechanical Engineering, Southwest Jiaotong University, Chengdu 610031, China \\ Correspondence should be addressed to Bo Lei; lbswjtu@163.com
}

Received 25 May 2018; Revised 24 August 2018; Accepted 16 September 2018; Published 1 November 2018

Academic Editor: Giulia Grancini

Copyright (C) 2018 Haofei Zhang et al. This is an open access article distributed under the Creative Commons Attribution License, which permits unrestricted use, distribution, and reproduction in any medium, provided the original work is properly cited.

\begin{abstract}
In this study, an exergy analysis of two kinds of solar-driven cogeneration systems consisting of solar collectors and an organic Rankine cycle (ORC) is presented for series mode and parallel mode. Three kinds of solar collectors are considered: flat-plate collectors (FPC), evacuated tube collectors (ETC), and parabolic trough collectors (PTC). This study mainly compares the exergy output of the two kinds of solar cogeneration systems under different temperatures of the return heating water and different inlet temperatures of the solar collectors. This study shows that, from the perspective of $W_{\text {net }}$ or $E$, the parallel mode is superior to the series mode. From the perspective of $E_{z}$, the parallel mode is superior to the series $\bar{m} \not d e$ when the solar collector is FPC; however, the series mode is superior to the parallel mode when the solar collector is PTC. When the solar collector is ETC, the result depends on the temperature of the return heating water. When the temperature of the return heating water is low (below $46^{\circ} \mathrm{C}$ ), the series mode is better, and when the temperature of the return heating water is high (above $46^{\circ} \mathrm{C}$ ), the parallel mode is better.
\end{abstract}

\section{Introduction}

A solar water heating system is a solar energy application that has drawn great attention among researchers in this field. In Lhasa, Tibet, China, known as "the city of sunlight," a number of buildings use solar water heating systems for heating in winter. However, the sunlight is very strong, and the cycle water is sometimes heated to boiling, as shown in Figure 1. Wang et al. [1] analyzed the problems of current solar heating systems in Lhasa and noted that sunlight exposure was the most common cause.

As there is no need for a cold supply in Lhasa in the summer, a good solution might be to transform the strong solar radiation into electrical power through solar collectors and thermal power plants during the nonheating season and parts of the heating season. This not only improves the reliability of the solar water heating system but also reduces the local consumption of fossil fuels and their impact on the ecological environment. However, the outlet temperature of solar collectors for heating systems is low for thermal power generation based on the Rankine cycle. The organic
Rankine cycle (ORC) enables efficient power generation units from low-grade heat sources by replacing water with organic working fluids, such as refrigerants or hydrocarbons. Thus, solar collectors and the ORC can form solar thermal power generation systems in the nonheating season and solardriven cogeneration systems in the heating season. This paper mainly discusses the solar-driven cogeneration system consisting of solar collectors and the ORC.

A few studies have examined solar collectors integrated with an ORC for electrical power production. Wang et al. $[2,3]$ proposed and tested a low-temperature solar ORC system utilizing R245fa as the working fluid. The overall power generation efficiency was $4.2 \%$ when the solar collectors were evacuated tube collectors (ETC), while it was $3.2 \%$ when using flat plate collectors (FPC). Al-Sulaiman et al. [4-6] studied a novel trigeneration system using parabolic trough collectors (PTC) and an ORC. The maximum electrical efficiency for the solar mode was $15 \%$, the solar and storage mode was $7 \%$, and the storage mode was $6.5 \%$; the maximum electrical-exergy efficiency was $7 \%$, the solar and storage mode was $3.5 \%$, and the storage mode was $3 \%$. He et al. [7] 

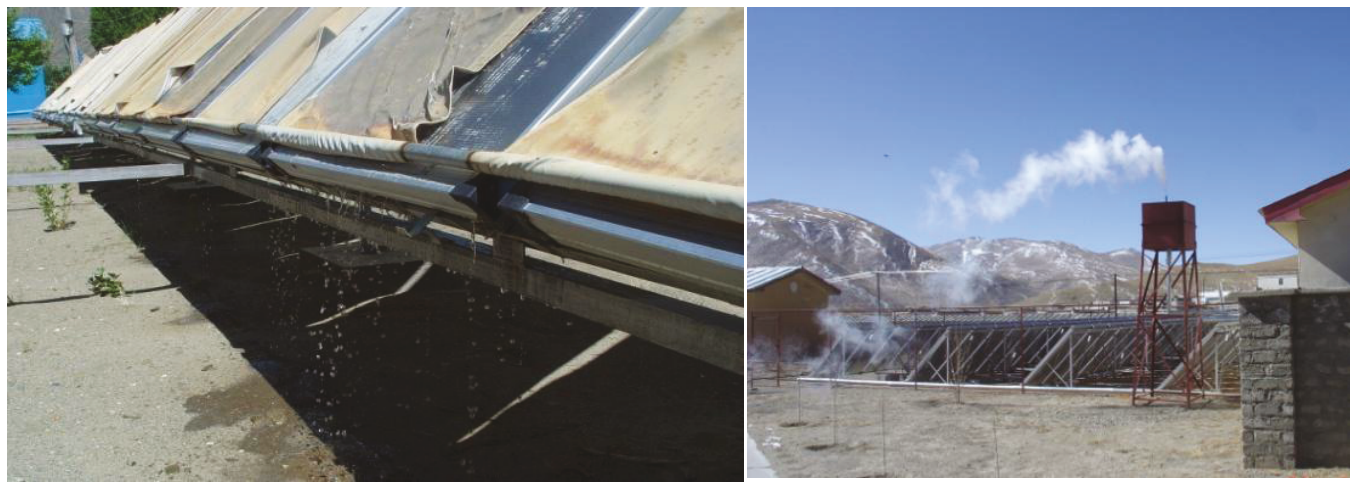

FIgURE 1: Overheating of solar collector systems in Lhasa.

built a model for a typical thermal power generation system with PTC and an ORC within the transient energy simulation package TRNSYS and found that pentane had the best performance among three organic working fluids: R113, R123, and pentane. Pei et al. $[8,9]$ reported that the overall electrical efficiency was approximately $8.6 \%$ when a solar irradiation of $750 \mathrm{~W} / \mathrm{m}^{2}$ was assumed for a low-temperature solar thermal electric generation system based on compound parabolic collectors (CPC) and an ORC. In a different study, Li et al. [10] noted that the optimal evaporation temperature and corresponding annual power output for Lhasa are $116^{\circ} \mathrm{C}$ and $163.42 \mathrm{kWh} / \mathrm{m}^{2}$, respectively, for a low-temperature solar thermal electric generation system mainly consisting of CPC and an ORC with R123.

It can be observed from the literature that the main form of the solar-driven cogeneration system is in series mode, as shown in Figure 2. The heating source for the heating system is the heat of condensation of the ORC system. However, the efficiency of collectors decreases with increasing inlet temperature of the fluid, and the efficiency of the ORC system decreases with increasing condensing temperature. Therefore, the series mode might not be the optimal form.

This paper proposes a new form of the solar-driven cogeneration system, the parallel mode, as shown in Figure 3. The solar water heating system and the solar ORC power generation system are connected in parallel. A portion of the solar collectors operate at low temperatures for heating, and the rest operate at high temperatures for power production. The solenoid valve VM is used to regulate the area of the collectors for heating or power generation. In this way, the efficiency of the collectors in the solar water heating system can be higher. In addition, the condensing temperature of the solar ORC power generation system is lower, which provides a higher power generation efficiency.

However, in parallel mode, a large amount of condensing heat is discharged into the environment. Therefore, it is not known whether the parallel mode has better thermodynamic performance than the series mode.

This paper mainly analyzes and compares the thermodynamic properties of the two kinds of solar-driven cogeneration systems: series mode and parallel mode.

\section{System Descriptions}

Figures 2 and 3 show the examined systems. Figure 2 shows the series mode, while Figure 3 shows the parallel mode. The examined systems are located in Lhasa, Tibet, China. Each mode is separated into 3 main parts: the solar collector field, the ORC system, and the heating system. All these parts are operated simultaneously to convert solar energy into electricity and heat.

The solar collector field consists of a number of solar collectors (FPC, ETC, or PTC). The working fluid is pressurized water to remain in the liquid phase in all cases, operating with a pressure of 5 bar. The water remains in the liquid phase even when its temperature reaches up to $150^{\circ} \mathrm{C}$ under this pressure [11]. To obtain an efficient ORC, the organic fluid should be carefully selected. A number of researches [12-16] have studied the selection of the ORC system. One of the typical recommended organic fluid types used to operate the ORC is R245fa. Hence, it is selected as the working fluid of the ORC.

The power generation of the two modes is similar, except that the condensing temperature of the ORC system is different. There are three main operating modes, which are controlled by the solenoid valves V1 V6:

(1) Solar mode: V2, V5, pump-1, on; V1, V3, V4, V6, pump-2, off

(2) Solar and storage mode: V1, V2, V4, V5, pump-1, on; V3, V6, pump-2, off

(3) Storage mode: V1, V2, V4, V5, pump-1, off; V3, V6, pump-2, on

The heating system in the two modes is different; the heating source of the series mode is the heat of condensation of the ORC system, and the source for the parallel mode is the solar collector system.

There are three main operating modes of the heating system in the series mode, which are controlled by the solenoid valves $\mathrm{V} 7 \sim \mathrm{V} 10$ :

(1) Heating mode: V7, V8, V9, V10, off; pump-3, on 


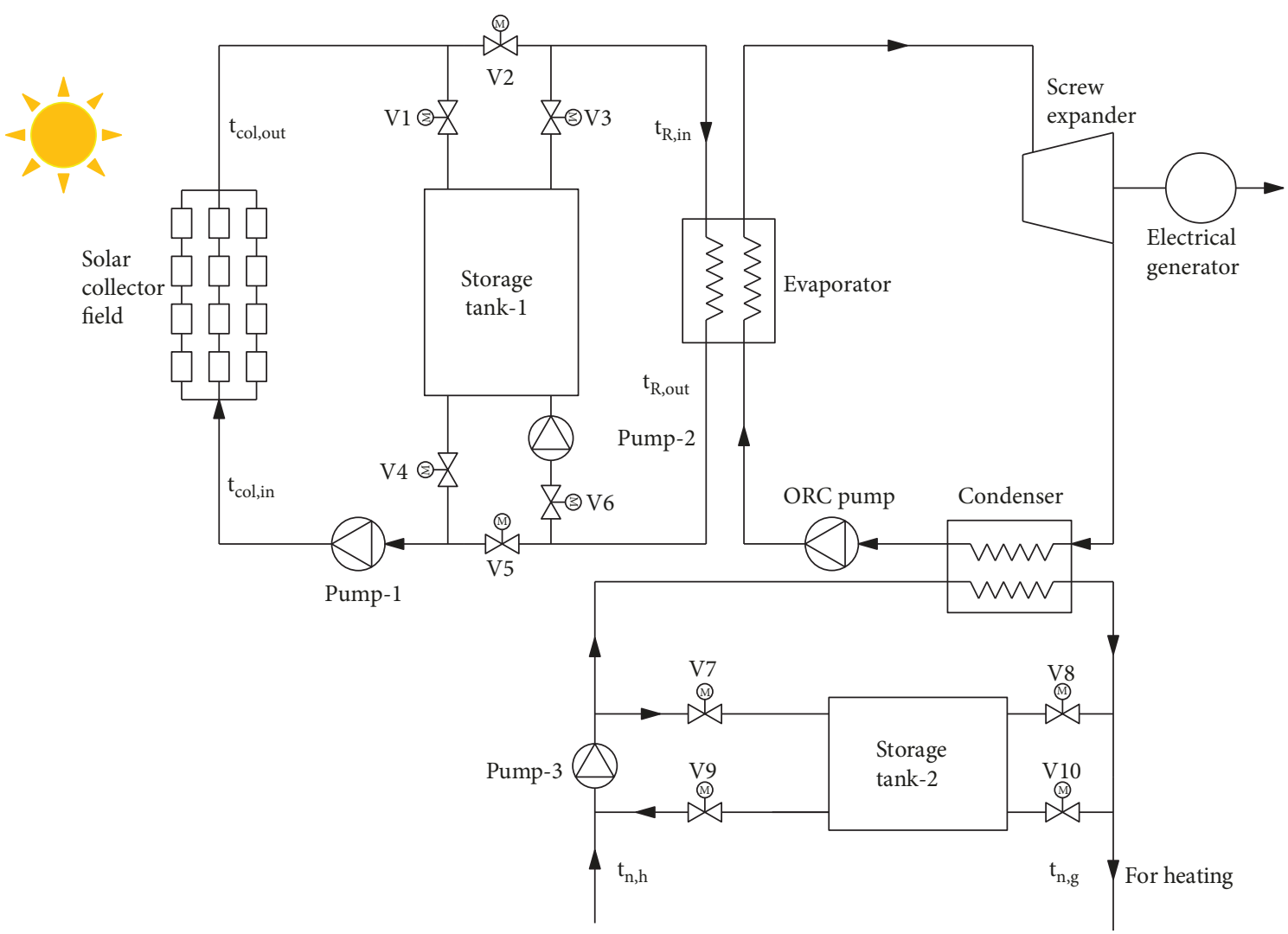

FIgURE 2: The series mode of the solar-driven cogeneration system.

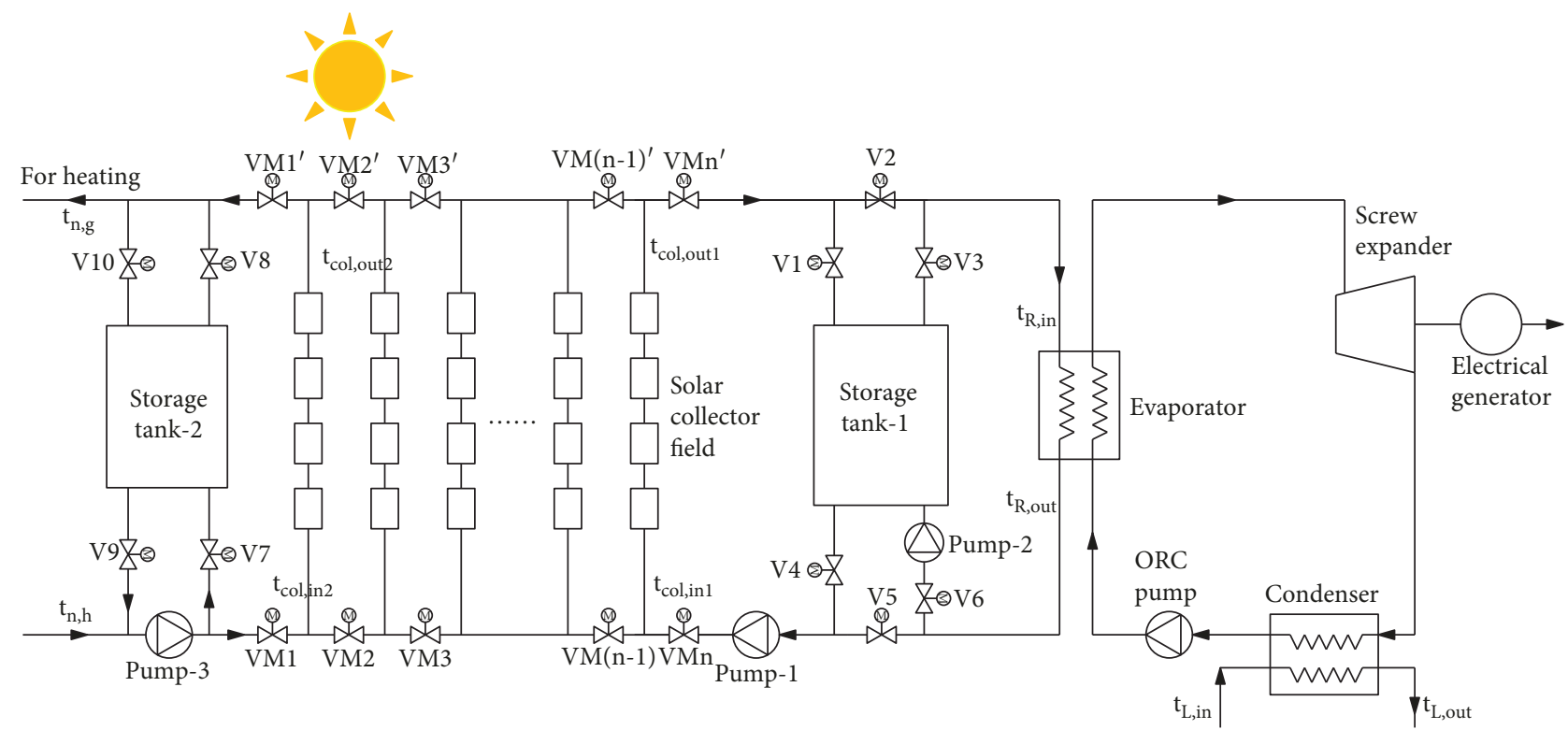

FIGURE 3: The parallel mode of the solar-driven cogeneration system.

(2) Heating and storage mode: V9, V10, pump-3, on; V7, V8, off

(3) Storage mode: V9, V10, off; V7, V8, pump-3, on

There are three main operating modes of the heating system in the parallel mode, which are controlled by the solenoid valves $\mathrm{V} 7 \sim \mathrm{V} 10$ and $\mathrm{VM} \sim \mathrm{VM}^{\prime}$ :
(1) Heating mode: V7, V8, V9, V10, off; pump-3, $\mathrm{VM} 1 \sim \operatorname{VM}(n)$ and $\mathrm{VM}^{\prime} \sim \operatorname{VM}(n)^{\prime}$, on

(2) Heating and storage mode: V7, V8, off; V9, V10, pump-3, $\mathrm{VM} 1 \sim \mathrm{VM}(n)$ and $\mathrm{VM}^{\prime} \sim \mathrm{VM}(n)^{\prime}$, on

(3) Storage mode: V9, V10, VM1 and VM1', off; V7, V8, pump-3, on 


\section{Mathematical Modeling}

3.1. Solar Collector. Solar energy is the energy source of the analyzed system. The solar energy potential of the solar field can be calculated from the collector aperture and the effective radiation. Equation (1) shows the available solar energy.

$$
Q_{\mathrm{sol}}=A_{\mathrm{col}} \cdot G_{\mathrm{eff}} \text {. }
$$

The effective radiation is different for every collector. FPC and ETC use both beam and diffuse radiation, while PTC only uses beam radiation. The effective radiation of every collector is presented as follows:

$$
G_{\mathrm{eff}}= \begin{cases}G_{\mathrm{til}} & \text { for FPC and ETC, } \\ G_{\text {PTC }} & \text { for PTC }\end{cases}
$$

The radiation in the tilted surface is given from (3) [17]. The symbol $G$ is used for the solar irradiance. The subscripts $b, n$, dif, and tot are as follows: $b$ and $n$ refer to the beam radiation on a plane normal to the direction of propagation; dif refers to the diffuse radiation; and tot refers to the total radiation on a horizontal surface. The symbol $\theta$ represents the angle of incidence, and $\beta$ represents the slope.

$$
\begin{aligned}
G_{\text {til }}= & G_{b, n} \cdot \cos (\theta)+G_{\text {dif }} \cdot\left(\frac{1+\cos (\beta)}{2}\right) \\
& +G_{\text {tot }} \cdot \rho \cdot\left(\frac{1-\cos (\beta)}{2}\right) .
\end{aligned}
$$

The radiation that PTC exploit is given as follows:

$$
G_{\mathrm{PTC}}=G_{b, n} \cdot \cos (\theta) \text {. }
$$

For a tilted surface, $\theta$ is given as follows:

$$
\begin{aligned}
\cos (\theta)= & \sin (\delta) \sin (\phi) \cos (\beta) \\
& -\sin (\delta) \cos (\phi) \sin (\beta) \cos (\gamma) \\
& +\cos (\delta) \cos (\phi) \cos (\beta) \cos (\omega) \\
& +\cos (\delta) \sin (\phi) \sin (\beta) \cos (\gamma) \cos (\omega) \\
& +\cos (\delta) \sin (\beta) \sin (\gamma) \sin (\omega) .
\end{aligned}
$$

$$
\eta_{c o l}=\left\{\begin{array}{l}
0.79-6.67 \cdot\left(\frac{t_{\mathrm{col}, \text { in }}-t_{a}}{G_{\mathrm{tit}}}\right) \text { for FPC, } \\
0.76-2.19 \cdot\left(\frac{t_{\mathrm{col}, \text { in }}-t_{a}}{G_{\mathrm{tit}}}\right) \text { for ETC, } \\
0.762-0.2125 \cdot\left(\frac{t_{\mathrm{col}, \mathrm{in}}-t_{\mathrm{a}}}{G_{\mathrm{PTC}}}\right)-0.001672 \cdot G_{\mathrm{PTC}} \cdot\left(\frac{t_{\mathrm{col}, \mathrm{in}}-t_{a}}{G_{\mathrm{PTC}}}\right)^{2} \text { for PTC. }
\end{array}\right.
$$

For a surface that can rotate around an axis in the east-west direction, $\theta$ is given as follows:

$$
\cos (\theta)=\sqrt{1-\cos ^{2}(\delta) \sin ^{2}(\omega)}
$$

where $\delta, \phi, \gamma$, and $\omega$ represent declination, latitude, azimuth angle, and solar hour angle, respectively. The declination $\delta$ can be found from the equation by Cooper [18]. The symbol $n$ refers to the day of the year.

$$
\delta=23.45^{\circ} \sin \left(360^{\circ} \times \frac{284+n}{365}\right)
$$

The solar hour angle $\omega$ can be calculated from the following:

$$
\begin{aligned}
\omega & =0.25^{\circ}(\mathrm{AST}-720), \\
\mathrm{AST} & =\mathrm{LST}+\mathrm{ET}-4(\mathrm{SL}-\mathrm{LL}), \\
\mathrm{ET} & =9.87 \sin (2 B)-7.53 \cos (B)-1.5 \sin (B), \\
B & =360^{\circ} \times \frac{(n-81)}{364},
\end{aligned}
$$

where AST and LST refer to solar time and local standard time, respectively. The symbols SL and LL refer to the standard meridian for the local time zone and the longitude of the location, respectively.

The thermal efficiency of the collector is the comparison of the useful energy that the working fluid absorbs to the solar energy delivered to the collector. Equation (9) presents this efficiency:

$$
\eta_{\mathrm{col}}=\frac{Q_{\mathrm{use}}}{Q_{\mathrm{sol}}}=\frac{c_{p, \mathrm{col}} \cdot m_{\mathrm{col}} \cdot\left(t_{\mathrm{col}, \mathrm{out}}-t_{\mathrm{col}, \mathrm{in}}\right)}{A_{\mathrm{col}} \cdot G_{\mathrm{eff}}} .
$$

For each collector type, a typical efficiency curve from the literature is selected [19-21], and (10) presents their efficiencies: 
3.2. ORC System. The thermal process of the ORC system is shown in Figure 4.

Processes $5-1$ in the evaporator are given by (11). The pinch point temperature of the evaporator can be described by $(12)$.

$$
\begin{aligned}
Q_{\text {evap }} & =m_{\text {org }} \cdot\left(h_{1}-h_{5}\right)=c_{p, \text { col }} \cdot m_{\text {col }} \cdot\left(t_{R, \text { in }}-t_{R, \text { out }}\right), \\
\Delta t_{\text {evap }} & =t_{8}-t_{6} .
\end{aligned}
$$

Processes 1-2 in the screw expander are given by

$$
W_{\mathrm{SE}}=m_{\mathrm{org}} \cdot\left(h_{1}-h_{2}\right) \cdot \eta_{\mathrm{SE}}
$$

Processes 2-4 in the condenser are given by

$$
Q_{\text {cond }}=m_{\text {org }} \cdot\left(h_{2}-h_{4}\right)=c_{p, \text { wat }} \cdot m_{\mathrm{wat}} \cdot\left(t_{L, \text { out }}-t_{L, \text { in }}\right) .
$$

The pinch point temperature of the condenser can be described by

$$
\Delta t_{\text {cond }}=t_{3}-t_{9}
$$

An evaporative condenser exchanges heat by both heat and mass transfer on the outside surface of the condenser tubes. A large part of the heat exchanged by the condenser comes from the evaporating water, so an evaporative condenser is mainly a wet bulb sensitive device [22]. The condensing temperature can be calculated by (16), where $T_{\mathrm{wb}}$ is the web bulb temperature of the outside air.

$$
t_{\text {cond }}=t_{\mathrm{wb}}+\left(t_{9}-t_{L, \text { in }}\right)+\Delta t_{\text {cond }} .
$$

According to the literature [23], the power consumption of the evaporative condenser is given by (17), where $W_{\mathrm{pu}}$ is the power consumption of the evaporative condenser per unit cooling load.

$$
W_{\text {cond }}=Q_{\text {cond }} \cdot W_{\mathrm{pu}} \text {. }
$$

Processes 4-5 in the ORC pump are given by

$$
W_{\mathrm{OP}}=\frac{m_{\mathrm{org}} \cdot\left(h_{5}-h_{4}\right)}{\eta_{\mathrm{OP}}} .
$$

The net power output of the ORC system is

$$
W_{\mathrm{ORC}}=W_{\mathrm{SE}}-W_{\mathrm{OP}}-W_{\text {cond }}
$$

The thermal efficiency of the ORC system can be calculated as

$$
\eta_{\mathrm{ORC}}=\frac{W_{\mathrm{ORC}}}{Q_{\text {evap }}}=\frac{W_{\mathrm{SE}}-W_{\mathrm{OP}}-W_{\text {cond }}}{c_{p, \mathrm{col}} \cdot m_{\mathrm{col}} \cdot\left(t_{R, \text { in }}-t_{R, \mathrm{out}}\right)}
$$

3.3. Exergy Analysis. For the solar-driven cogeneration system, the energy level of the two kinds of output, heat and electricity, is different. Therefore, this paper uses the exergy

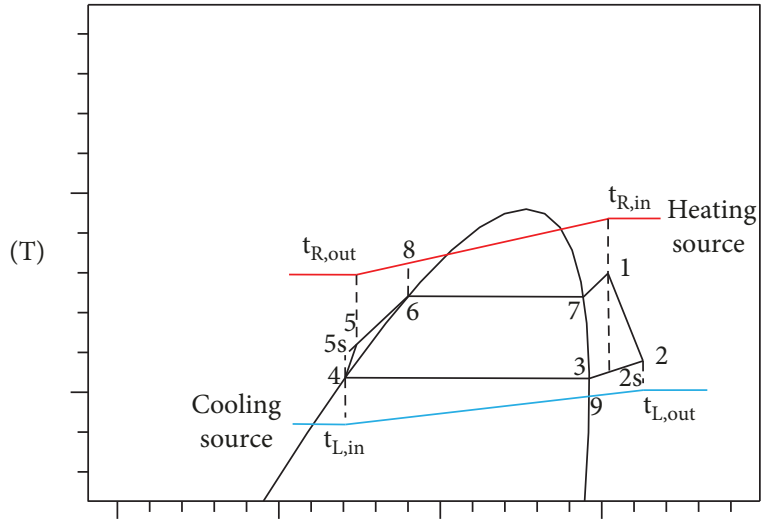

(s)

FIgURe 4: T-s diagram of an ORC.

TABLE 1: Other parameters of the analysis system.

\begin{tabular}{lccc}
\hline Parameter & Value & Parameter & Value \\
\hline$\phi$ & $29.5^{\circ}$ & $\Delta t_{\text {cond }}$ & $3^{\circ} \mathrm{C}$ \\
$\mathrm{LL}$ & $91.1^{\circ}$ & $W_{\mathrm{pu}}$ & $11.12 \mathrm{~W} / \mathrm{kW}$ \\
$\mathrm{SL}$ & $120^{\circ}$ & $\eta_{\mathrm{SE}}$ & $0.85[13]$ \\
$n$ & 172 & $H_{1}$ & $15 \mathrm{~m}$ \\
$\gamma$ & 0 & $H_{2}$ & $15 \mathrm{~m}$ \\
$\beta$ & $40^{\circ}$ & $H_{3}$ & $30 \mathrm{~m}$ \\
$\rho$ & 0.2 & $r$ & $9.8 \mathrm{kN} / \mathrm{m}^{3}$ \\
$\Delta t_{\text {evap }}$ & $3^{\circ} \mathrm{C}$ & $\eta_{p(i)}$ & 0.6 \\
\hline
\end{tabular}

analysis method to compare the two kinds of solar-driven cogeneration systems.

The exergy of the output electricity is

$$
W_{\text {net }}=W_{\text {ORC }}-W_{p 1}-W_{p 2}-W_{p 3} \text {, }
$$

where $W_{p 1}, W_{p 2}$, and $W_{p 3}$ represent the power consumption of the pumps (pump-1, pump-2, and pump-3, respectively, in Figures 2 and 3).

$$
W_{p(i)}=\frac{r Q_{(i)} H_{(i)}}{\eta_{p(i)}}
$$

where $Q_{p(i)}, H_{p(i)}$, and $\eta_{p(i)}$ represent the flow rate, hydraulic head, and efficiency of the pumps, respectively, and $r$ represents the volume weight of the working fluid.

The exergy of the output heat is

$$
E_{n}=c_{n} \cdot m_{n} \cdot\left[\left(t_{n, g}-t_{n, h}\right)-t_{a} \cdot \ln \left(\frac{t_{n, g}}{t_{n, h}}\right)\right] \text {, }
$$

where $c_{n}$ represents the specific heat of the heating water, in $\mathrm{kJ} / \mathrm{kg} \cdot \mathrm{K} ; m_{n}$ represents the mass flow rate of the heating water, in $\mathrm{kg} / \mathrm{s}$; and $t_{n, g}$ and $t_{n, h}$ represent the temperature of the supply and return heating water, in $\mathrm{K}$. 


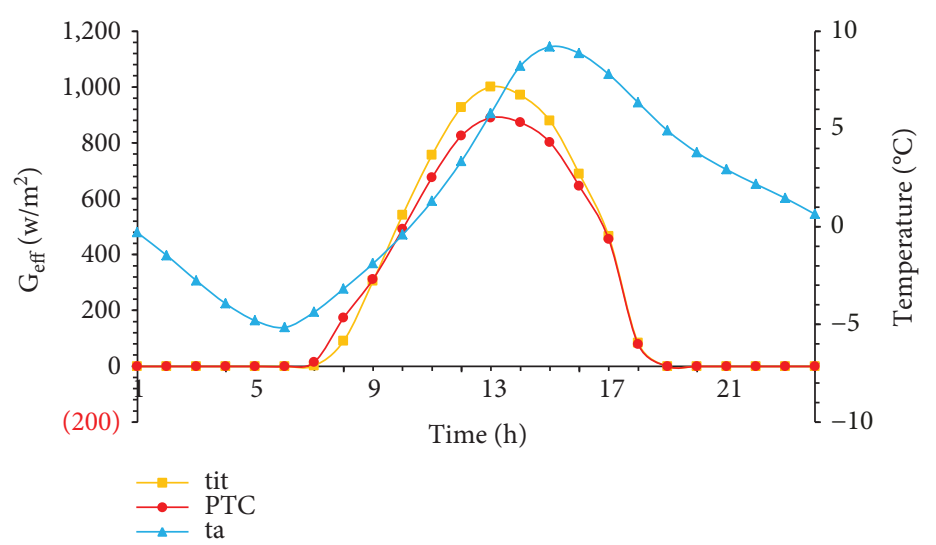

FIgURE 5: Average meteorological data for the heating season.

The total exergy is

$$
E_{z}=W_{\text {net }}+E_{n}
$$

3.4. Simulation Parameters. For the meteorological data in the simulation, the values of $G_{b, n}, G_{\text {dif }}, G_{\text {tot }}$, and ambient temperature use TMY data that are taken from Meteonorm software. The other parameters (the latitude of the place, the slope angle of the collectors, and the ground reflectance) are shown in Table 1. FPC and ETC are sloped, while PTC are horizontal with the axis in the east-west direction and a tracking system for movement in the north-south direction.

As there is no document to specify the design day, this paper takes the average meteorological data of the heating season for analysis. Figure 5 shows the average meteorological data.

The optimization parameter of this system is the inlet temperature of the pressurized water in the collectors. This parameter determines the collector efficiency and influences the outlet temperature of the collectors. The outlet and inlet temperatures of the collectors are the inlet and outlet temperatures of the evaporator of the ORC system, respectively, which determines the efficiency of the ORC system. A high inlet temperature for the collectors decreases the collector thermal efficiency but increases the efficiency of the ORC system. Thus, an optimization of this temperature is needed to design an optimum system. Four different simulations, one for each collector type, are presented in this study. It is essential to mention that the solar potential is different from case to case because each collector type utilizes the diffuse radiation in a different way, which has been presented in (2). The analysis is performed under steady-state conditions using MATLAB and REFPROP.

\section{Results and Discussions}

All the simulation results are presented and analyzed to determine which kind of solar-driven cogeneration system has better thermodynamic properties.

4.1. Collector Performance. The collector efficiency depends on the operating conditions, among which the effective radiation and the water inlet temperature are two crucial parameters. Figure 5 shows the effective irradiance of every collector. Apparently, the effective radiation of the collectors changes with time. Before 7:00 and after 19:00, there was no effective irradiance. The effective irradiance increases in the morning from 7:00 until it reaches a maximum value and then decreases until 19:00. The maximum effective irradiance of every collector occurs at 13:00. The effective irradiance of PTC is higher than that of FPC and ETC from 7:00 to 9:00 but lower from 9:00 to 19:00.

Figure 6 shows the efficiency of each collector under different inlet temperature conditions. It is obvious that the efficiency decreases with increasing inlet temperature. PTC are the most efficient technology with ETC being the second. FPC follow with a lower efficiency. For higher inlet temperature levels, the performance of FPC is very low because the heat losses are very large. PTC and ETC use evacuated tubes, so the heat losses remain low for the entire examined temperature region.

Figure 7 shows the collected heat of collectors with a $1 \mathrm{~m}^{2}$ collector area at different inlet temperatures on the analyzed day. It can be seen from the figure that the collected heat decreases with increasing inlet temperature, and FPC decreases the most while PTC decreases the least. Therefore, for the solar-driven cogeneration system with FPC, the parallel mode can significantly improve the collected heat. However, for ETC or PTC, the improvement is not as significant.

4.2. ORC Performance. For the ORC system, the temperatures of the heat source and the cold source are two crucial parameters for the thermal efficiency. Figure 8 depicts the influence of inlet temperature on the thermal efficiency of the ORC system in parallel mode and series mode.

A higher temperature of the heat source leads to a higher efficiency. A higher temperature of the heat source corresponds to a higher inlet temperature of the solar collectors. Apparently, the thermal efficiency increases with the inlet temperature up to $145^{\circ} \mathrm{C}$ because the critical temperature of $\mathrm{R} 245 \mathrm{fa}$ is $154^{\circ} \mathrm{C}$.

Figure 8 shows that the efficiency of the ORC system in the parallel mode is significantly higher than that in the series mode. As the heating temperature increased, the efficiency of 

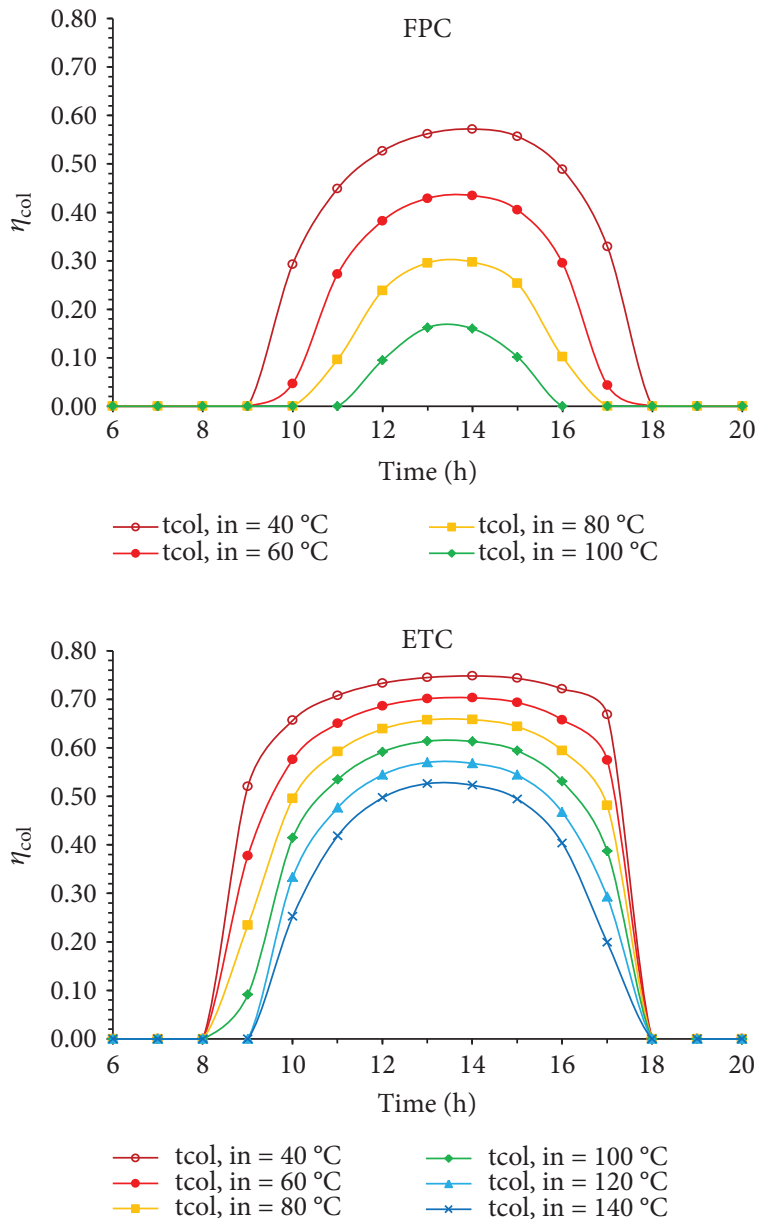

PTC

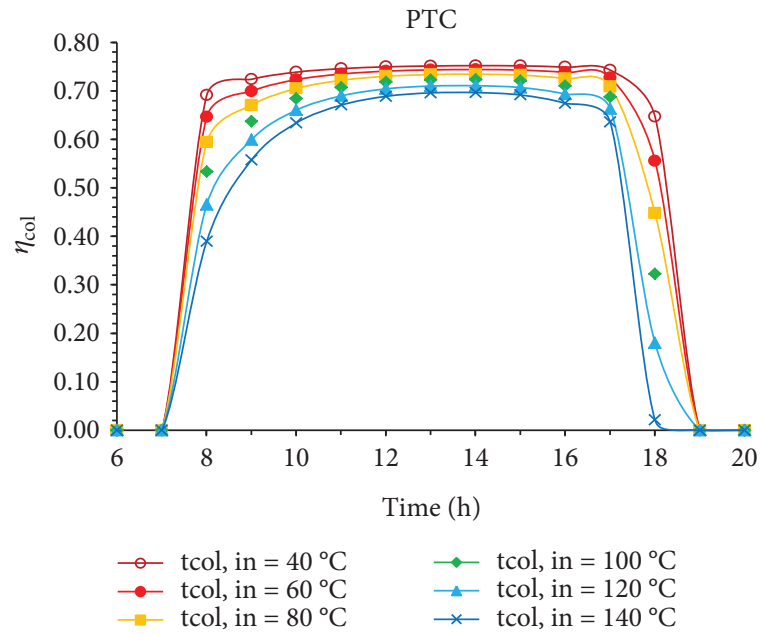

FIGURE 6: Efficiency of each collector for various inlet temperatures.

the ORC system in the series mode gradually decreased. The reason is that the condensing temperature of the ORC system in the parallel mode is the wet bulb temperature of the air, which is much lower than that in the series mode.

4.3. Series Mode of the Solar-Driven Cogeneration System. For the series mode of the solar-driven cogeneration system, the inlet temperature of the collectors and the temperature of

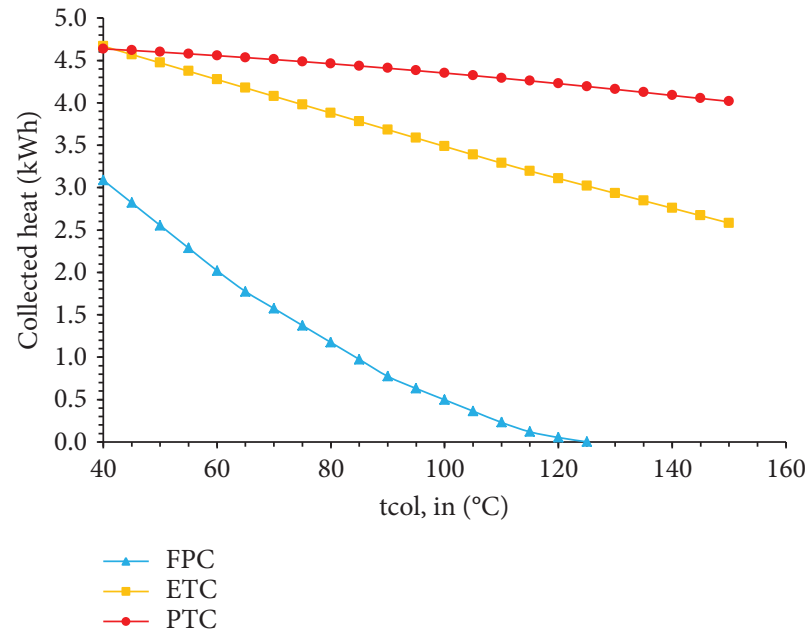

FIgURE 7: Collected heat by a $1 \mathrm{~m}^{2}$ collector area on the analyzed day.

the return heating water are two crucial parameters for the thermal performance. Figure 9 depicts the influence of inlet temperature on the exergy output of the series mode of the solar-driven cogeneration system when the temperature of the return heating water is $40^{\circ} \mathrm{C}$.

Figure 9 shows that for the three types of solar collectors, the output exergy could be ranked from high to low: $E_{z}>$ $E_{n}>W_{\text {net }}$.

For FPC, with the increase of the inlet temperature of the collectors, $W_{\text {net }}$ increases until it reaches a maximum value and then decreases. $E_{n}$ and $E_{z}$ decrease with the increase of the inlet temperature of the collectors. The optimum inlet temperature for $\mathrm{FPC}$ is $65^{\circ} \mathrm{C}$, and the maximum $E_{z}$ is $0.265 \mathrm{kWh}$.

For ETC and PTC, with the increase of the inlet temperature of the collectors, $W_{\text {net }}$ and $E_{z}$ increase until they reach a maximum value and then decrease. $E_{n}$ decreases with the increase of the inlet temperature of the collectors. The optimum inlet temperature for ETC is $85^{\circ} \mathrm{C}$, and the maximum $E_{z}$ is $0.657 \mathrm{kWh}$. The optimum inlet temperature for PTC is $135^{\circ} \mathrm{C}$, and the maximum $E_{z}$ is $0.850 \mathrm{kWh}$.

4.4. Parallel Mode of the Solar-Driven Cogeneration System. For the parallel mode of the solar-driven cogeneration system, a portion of the solar collectors operate at low temperatures for heating, and the rest operate at high temperatures for power production. The inlet temperature of the collectors for heating is the temperature of the return heating water, which is $40^{\circ} \mathrm{C}$. The inlet temperature of the collectors for power production is the optimum temperature, which is $60^{\circ} \mathrm{C}$ for FPC, $100^{\circ} \mathrm{C}$ for ETC, and $140^{\circ} \mathrm{C}$ for PTC.

For the parallel mode of the solar-driven cogeneration system, the proportion of the solar collector area that is used for heating and power production is a crucial parameter for the thermal performance.

Figure 10 shows that for the three types of solar collectors, $E_{n}$ and $E_{z}$ increase while $W_{\text {net }}$ decreases with an increasing proportion of solar collector area for heating. That is, the exergy output of the solar heating system is higher than that 


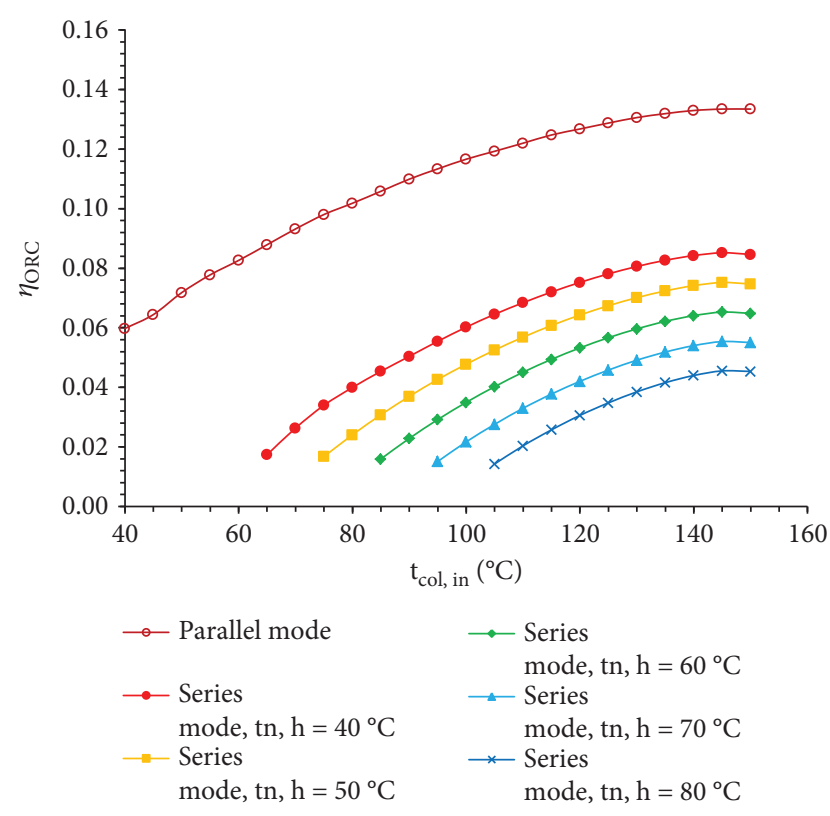

Figure 8: Efficiency of the ORC system.

of the solar power production system when the solar collector area is the same. $E_{z}\left(E_{n}\right)$ reaches the maximum when all the collectors are used for heating, and $W_{\text {net }}$ reaches the maximum when all the collectors are used for power production.

4.5. Comparison of the Two Kinds of Solar-Driven Cogeneration Systems. Figure 11 shows the maximum exergy output of the two modes of the solar-driven cogeneration system with a $1 \mathrm{~m}^{2}$ collector area on the analyzed day at different temperatures of the return heating water. The value beside each point in Figure 11 indicates the optimum inlet temperature of the collectors for the maximum exergy output in series mode. The optimum proportion of solar collector area for heating is 1 for $E_{n}\left(E_{z}\right)$ and 0 for $W_{\text {net }}$ in parallel mode.

In the series mode, for the three types of solar collectors, the maximum $W_{\text {net }}$ decreases with the increase of the temperature of the return heating water. The reason is that the condensing temperature increases with increasing temperature of the return heating water, which decreases the power generation efficiency. For FPC, the maximum $E_{z}$ decreases with increasing temperature of the return heating water. When $t_{n, h}=40^{\circ} \mathrm{C}$, the maximum $E_{z}$ is $0.265 \mathrm{kWh}$; when $t_{n, h}=60^{\circ} \mathrm{C}$, the maximum $E_{z}$ is $0.194 \mathrm{kWh}$; and when $t_{n, h}$ $=80^{\circ} \mathrm{C}$, the maximum $E_{z}$ is $0.088 \mathrm{kWh}$. For ETC and PTC, the maximum $E_{z}$ increases with increasing temperature of the return heating water. For ETC, when $t_{n, h}=40$ ${ }^{\circ} \mathrm{C}$, the maximum $E_{z}$ is $0.657 \mathrm{kWh}$; when $t_{n, h}=60^{\circ} \mathrm{C}$, the maximum $E_{z}$ is $0.754 \mathrm{kWh}$; and when $t_{n, h}=80^{\circ} \mathrm{C}$, the maximum $\mathrm{E}_{\mathrm{z}}$ is $0.823 \mathrm{kWh}$. For $\mathrm{PTC}$, when $t_{n, h}=40^{\circ} \mathrm{C}$, the maximum $E_{z}$ is $0.850 \mathrm{kWh}$; when $t_{n, h}=60^{\circ} \mathrm{C}$, the maximum $E_{z}$ is $0.976 \mathrm{kWh}$; and when $t_{n, h}=80^{\circ} \mathrm{C}$, the maximum $E_{z}$ is $1.088 \mathrm{kWh}$.

In the parallel mode, for the three types of solar collectors, the maximum $W_{\text {net }}$ remains the same with the increase
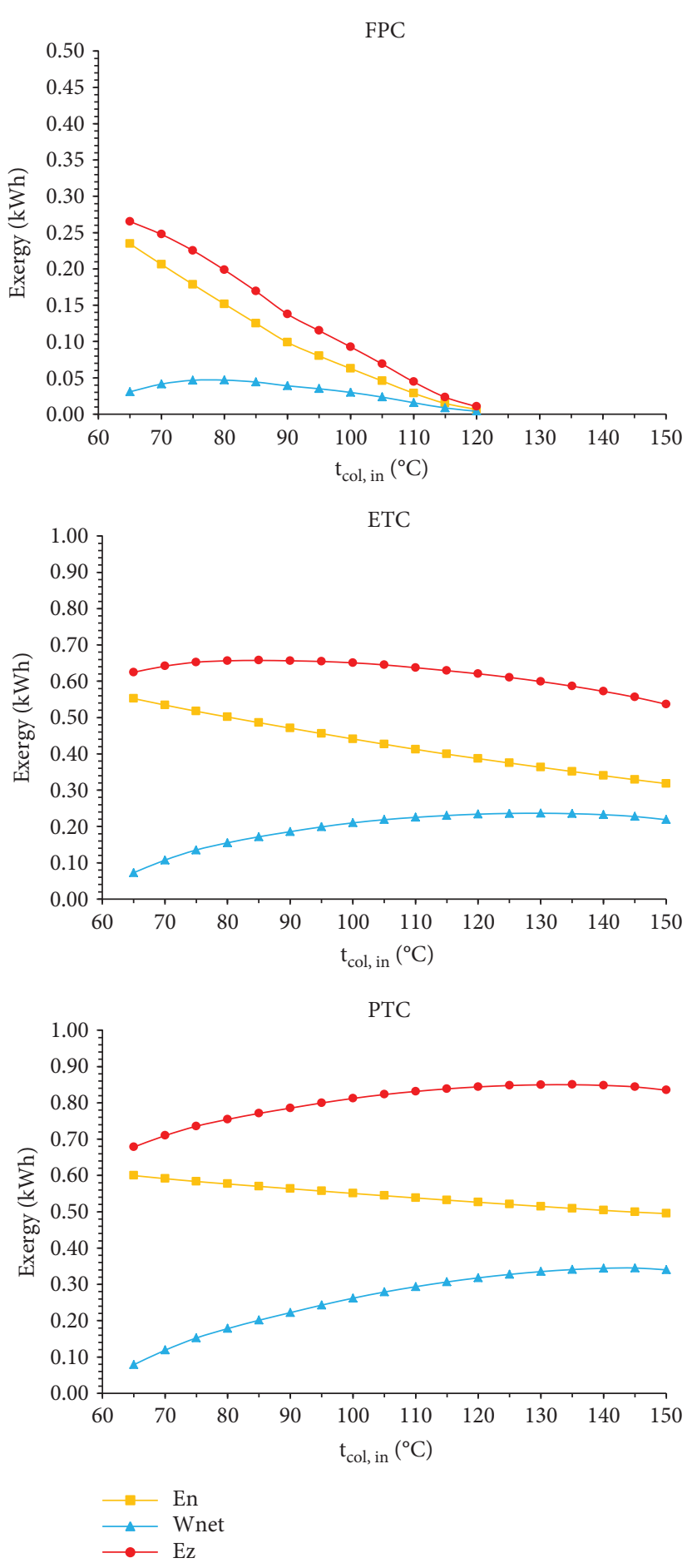

FIgURe 9: Output exergy for a $1 \mathrm{~m}^{2}$ collector area on the analyzed day $\left(t_{n, h}=40^{\circ} \mathrm{C}\right)$.

of the temperature of the return heating water because all the solar collectors are used for power production and none for heating. For FPC, the maximum $E_{z}$ decreases with increasing temperature of the return heating water. When $t_{n, h}=40^{\circ} \mathrm{C}$, the maximum $E_{z}$ is $0.415 \mathrm{kWh}$; when $t_{n, h}=60^{\circ} \mathrm{C}$, the maximum $E_{z}$ is $0.376 \mathrm{kWh}$; and when $t_{n, h}=80^{\circ} \mathrm{C}$, the maximum $E_{z}$ is $0.272 \mathrm{kWh}$. For ETC and PTC, the maximum $E_{z}$ 

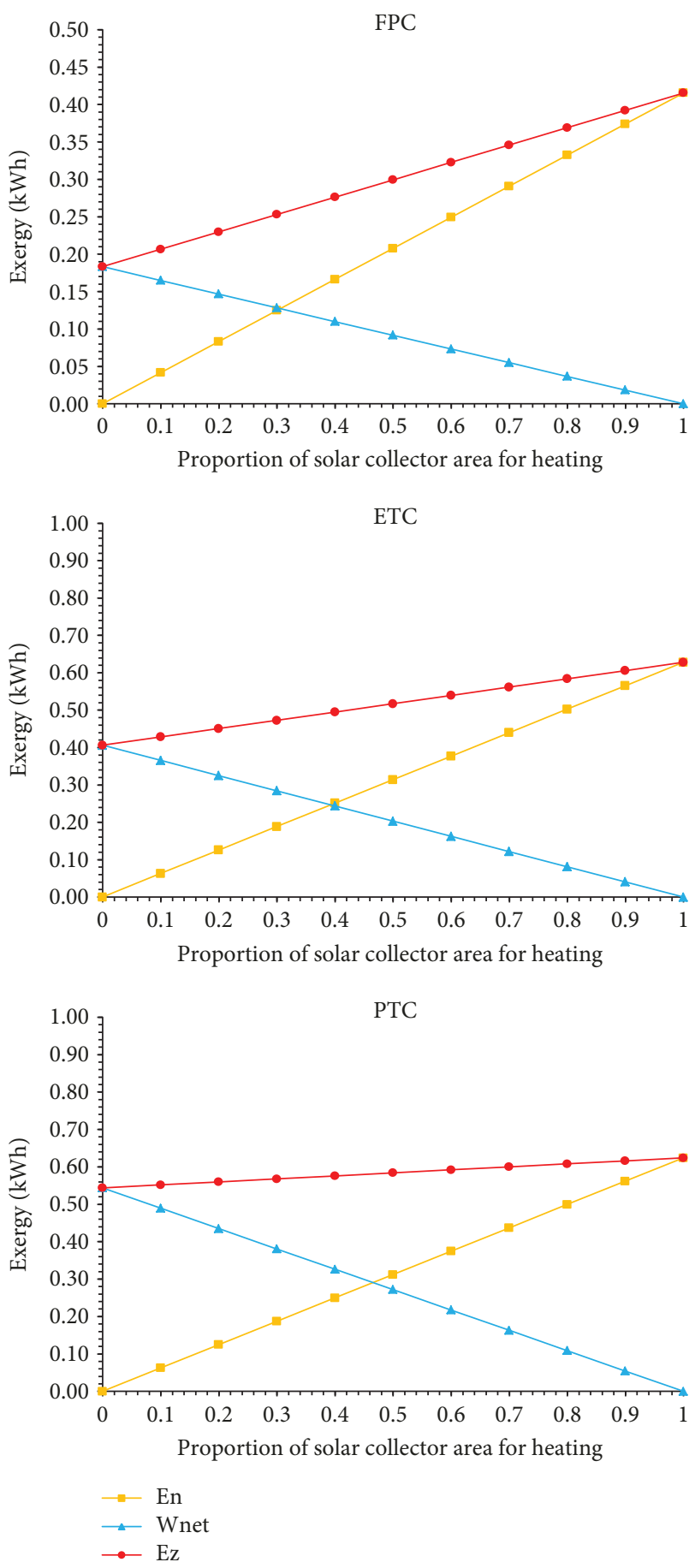

FIGURE 10: Output exergy for a $1 \mathrm{~m}^{2}$ collector area on the analyzed day $\left(t_{n, h}=40^{\circ} \mathrm{C}\right)$.

increases with increasing temperature of the return heating water. For ETC, when $t_{n, h}=40^{\circ} \mathrm{C}$, the maximum $E_{z}$ is $0.628 \mathrm{kWh}$; when $t_{n, h}=60^{\circ} \mathrm{C}$, the maximum $\mathrm{E}_{\mathrm{z}}$ is $0.795 \mathrm{kWh}$; and when $t_{n, h}=80^{\circ} \mathrm{C}$, the maximum $E_{z}$ is $0.900 \mathrm{kWh}$. For PTC, when $t_{n, h}=40^{\circ} \mathrm{C}$, the maximum $E_{z}$ is $0.624 \mathrm{kWh}$; when $t_{n, h}=60^{\circ} \mathrm{C}$, the maximum $E_{z}$ is $0.848 \mathrm{kWh}$; and when $t_{n, h}=$ $80^{\circ} \mathrm{C}$, the maximum $E_{z}$ is $1.035 \mathrm{kWh}$.
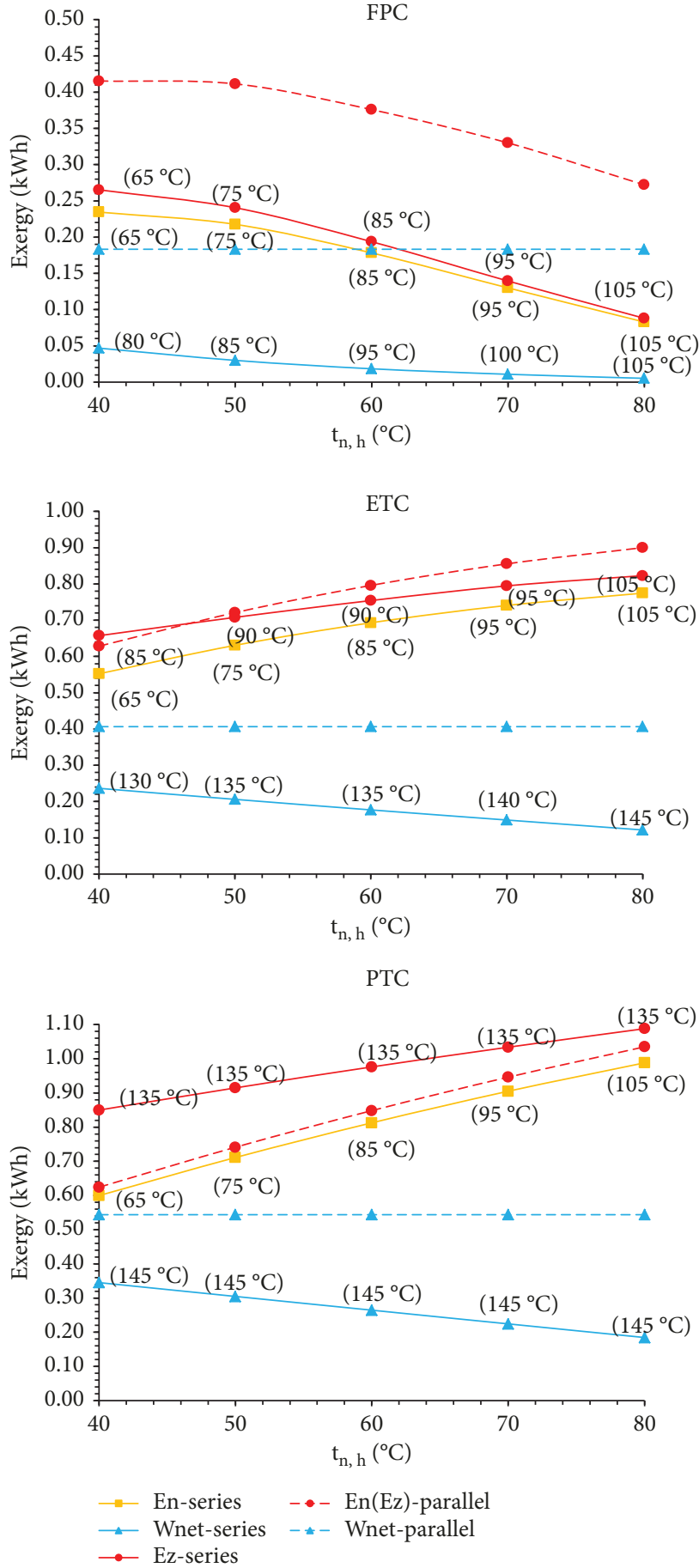

FIgURE 11: Maximum output exergy of two kinds of solar-driven cogeneration systems with a $1 \mathrm{~m}^{2}$ collector area on the analyzed day.

Make $\Delta E_{n}=\left(E_{n}-\right.$ series $)-\left(E_{n}-\right.$ parallel $), \Delta W_{\text {net }}=\left(W_{\text {net }}\right.$ - series $)-\left(W_{\text {net }}-\right.$ parallel $)$, and $\Delta E_{z}=\left(E_{z}\right.$ - series $)-$ $\left(E_{z}\right.$ - parallel $)$, and then $\Delta E_{n}, \Delta W_{\text {net }}$, and $\Delta E_{z}$ of the three collector types are shown in Figure 12. From Figure 12, it can be seen that from the perspective of $W_{\text {net }}$ or $E_{n}$, the parallel mode is superior to the series mode. From the perspective of $E_{z}$, the parallel mode is superior to the series mode when the solar collector is FPC; however, the series mode 


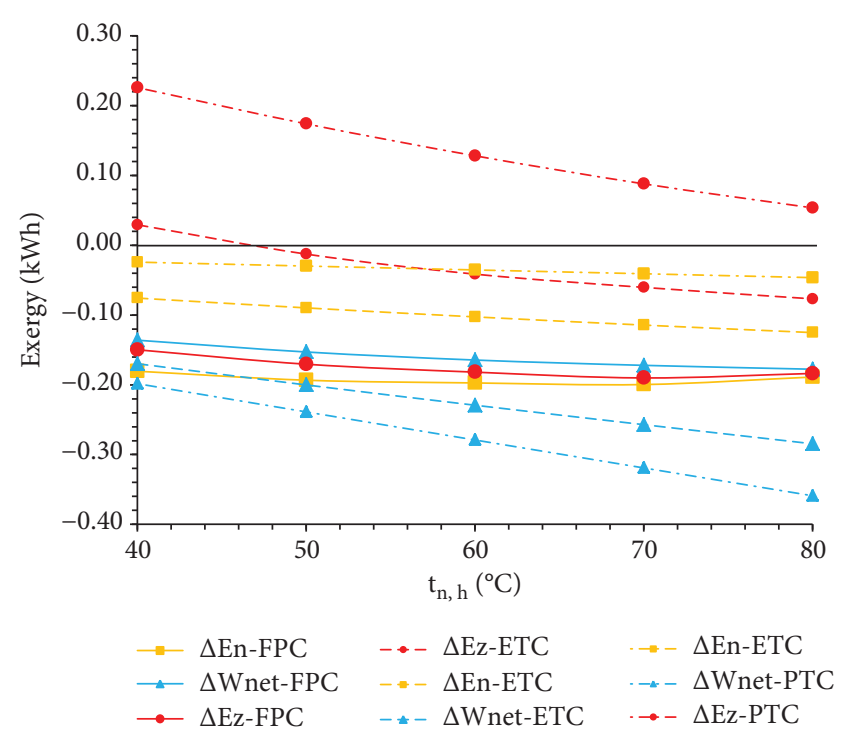

Figure 12: $\Delta E_{n}, \Delta W_{\text {net }}$, and $\Delta E_{z}$ of the three collector types.

is superior to the parallel mode when the solar collector is PTC. When the solar collector is ETC, the result depends on the temperature of the return heating water. When the temperature of the return heating water is low (below $46^{\circ} \mathrm{C}$ ), the series mode is better, and when the temperature of the return heating water is high (above $46^{\circ} \mathrm{C}$ ), the parallel mode is better.

\section{Conclusions}

The performance of two kinds of solar-driven cogeneration systems consisting of solar collectors and an ORC is compared and analyzed for series mode and parallel mode. Three kinds of solar collectors are considered: FPC, ETC, and PTC. The exergy outputs of the two kinds of solar cogeneration systems under different temperatures of the return heating water and different inlet temperatures of the solar collectors are calculated and compared. The main results of this study are summarized below:

(1) In the series mode, with the increase of the inlet temperature of the collectors, the total exergy output decreases for FPC and increases until it reaches a maximum value and then decreases for ETC and PTC

(2) In the parallel mode, the total exergy output increases with the increase of the proportion of solar collector area for heating. The exergy output of the solar heating system is higher than that of the solar power production system when the solar collector areas are the same

(3) From the perspective of $W_{\text {net }}$ or $E_{n}$, the parallel mode is superior to the series mode

(4) From the perspective of $E_{z}$, the parallel mode is superior to the series mode when the solar collector is
FPC; however, the series mode is superior to the parallel mode when the solar collector is PTC. When the solar collector is ETC, the result depends on the temperature of the return heating water. When the temperature of the return heating water is low (below $46^{\circ} \mathrm{C}$ ), the series mode is better, and when the temperature of the return heating water is high (above $46^{\circ} \mathrm{C}$ ), the parallel mode is better

\section{Nomenclature}

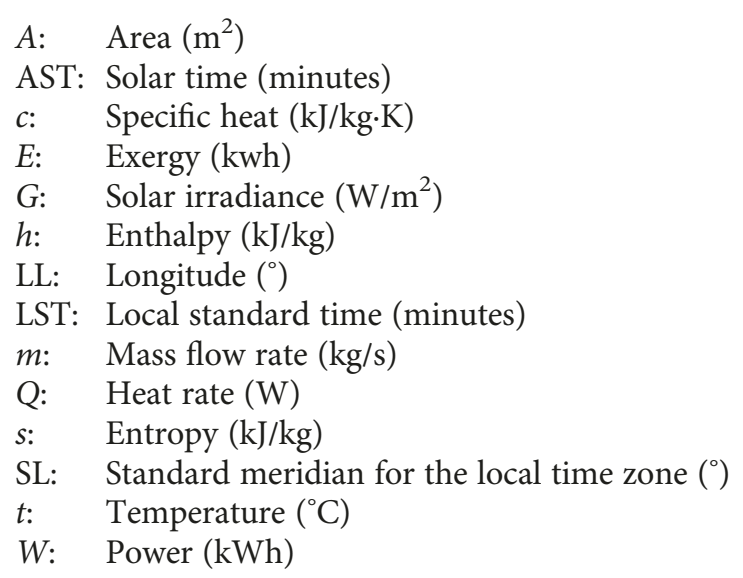

\section{Greek Letters}

$\beta$ : Collector slope $\left({ }^{\circ}\right)$

$\gamma$ : Azimuth angle $\left({ }^{\circ}\right)$

$\delta$ : Declination angle $\left({ }^{\circ}\right)$

$\eta$ : Efficiency

$\theta$ : Angle of incidence $\left(^{\circ}\right)$

$\rho$ : Ground reflectance

$\omega$ : Solar hour angle $\left(^{\circ}\right)$

$\phi$ : Latitude $\left(^{\circ}\right)$

\section{Subscripts and Superscripts}

$a: \quad$ Ambient

$b, n$ : Beam radiation on a plane normal to the direction of propagation

col: Collector

cond: Condenser

dif: Diffuse radiation

eff: Effective

evap: Evaporator

in: Inlet

$L$ : $\quad$ Cooling source

OP: Organic pump

org: Organic fluid

out: Outlet

$R: \quad$ Heating source

SE: Screw expander

sol: Solar energy

til: $\quad$ Tilted surface

tot: Total radiation on a horizontal surface

use: Useful

wat: Water

wb: Wet bulb. 


\section{Data Availability}

The meteorological data used to support the findings of this study are included within the article.

\section{Conflicts of Interest}

The authors declare that there is no conflict of interest regarding the publication of this paper.

\section{Acknowledgments}

This work was supported by the Sichuan Province Youth Science and Technology Innovation Team of Building Environment and Energy Efficiency (no. 2015TD0015).

\section{References}

[1] L. Wang, L. Yuan, C. M. Zhu, Z. R. Li, and N. Y. Yu, "Necessity of the whole process commissioning for active solar heating systems," Heating, Ventilating and Air Conditioning, vol. 42, pp. 53-56, 2012.

[2] X. D. Wang, L. Zhao, J. L. Wang, W. Z. Zhang, X. Z. Zhao, and $\mathrm{W}$. Wu, "Performance evaluation of a low-temperature solar Rankine cycle system utilizing R245fa," Solar Energy, vol. 84, no. 3, pp. 353-364, 2010.

[3] X. D. Wang, L. Zhao, and J. L. Wang, "Experimental investigation on the low-temperature solar Rankine cycle system using R245fa," Energy Conversion and Management, vol. 52, no. 2, pp. 946-952, 2011.

[4] F. A. Al-Sulaiman, I. Dincer, and F. Hamdullahpur, "Exergy modeling of a new solar driven trigeneration system," Solar Energy, vol. 85, no. 9, pp. 2228-2243, 2011.

[5] F. A. Al-Sulaiman, F. Hamdullahpur, and I. Dincer, "Performance assessment of a novel system using parabolic trough solar collectors for combined cooling, heating, and power production," Renewable Energy, vol. 48, pp. 161-172, 2012.

[6] F. A. Al-Sulaiman, "Exergy analysis of parabolic trough solar collectors integrated with combined steam and organic Rankine cycles," Energy Conversion and Management, vol. 77, pp. 441-449, 2014.

[7] Y. L. He, D. H. Mei, W. Q. Tao, W. W. Yang, and H. L. Liu, "Simulation of the parabolic trough solar energy generation system with organic Rankine cycle," Applied Energy, vol. 97, pp. 630-641, 2012.

[8] G. Pei, J. Li, and J. Ji, "Analysis of low temperature solar thermal electric generation using regenerative organic Rankine cycle," Applied Thermal Engineering, vol. 30, no. 8-9, pp. 9981004, 2010.

[9] P. Gang, L. Jing, and J. Jie, "Design and analysis of a novel lowtemperature solar thermal electric system with two-stage collectors and heat storage units," Renewable Energy, vol. 36, no. 9, pp. 2324-2333, 2011.

[10] L. Jing, P. Gang, and J. Jie, "Optimization of low temperature solar thermal electric generation with organic Rankine cycle in different areas," Applied Energy, vol. 87, no. 11, pp. 33553365, 2010.

[11] E. Bellos, C. Tzivanidis, and K. A. Antonopoulos, "Exergetic, energetic and financial evaluation of a solar driven absorption cooling system with various collector types," Applied Thermal Engineering, vol. 102, pp. 749-759, 2016.
[12] B. T. Liu, K. H. Chien, and C. C. Wang, "Effect of working fluids on organic Rankine cycle for waste heat recovery," Energy, vol. 29, no. 8, pp. 1207-1217, 2004.

[13] B. Saleh, G. Koglbauer, M. Wendland, and J. Fischer, "Working fluids for low-temperature organic Rankine cycles," Energy, vol. 32, no. 7, pp. 1210-1221, 2007.

[14] P. J. Mago, L. M. Chamra, and C. Somayaji, "Performance analysis of different working fluids for use in organic Rankine cycles," Proceedings of the Institution of Mechanical Engineers, Part A: Journal of Power and Energy, vol. 221, no. 3, pp. 255263, 2007.

[15] P. J. Mago, K. K. Srinivasan, L. M. Chamra, and C. Somayaji, "An examination of exergy destruction in organic Rankine cycles," International Journal of Energy Research, vol. 32, no. 10, pp. 926-938, 2008.

[16] H. Hajabdollahi, A. Ganjehkaviri, and M. N. Mohd Jaafar, "Thermo-economic optimization of RSORC (regenerative solar organic Rankine cycle) considering hourly analysis," Energy, vol. 87, pp. 369-380, 2015.

[17] S. Kalogirou, Solar Energy Engineering, Academic Press, Boston, 2009.

[18] J. A. Duffie and W. A. Beckman, Eds., Solar Engineering of Thermal Processes,, Wiley, Hoboken, NJ, USA, third edition, 2006.

[19] S. Kalogirou, "The potential of solar industrial process heat applications," Applied Energy, vol. 76, no. 4, pp. 337-361, 2003.

[20] S. A. Kalogirou, "Solar thermal collectors and applications," Progress in Energy and Combustion Science, vol. 30, no. 3, pp. 231-295, 2004.

[21] V. Dudley, SANDIA Report Test Results for Industrial Solar Technology Parabolic Trough Solar Collector [SAND94-1117], Sandia National Laboratory, Albuquerque, USA, 1995.

[22] K. Manske, Performance Optimization of Industrial Refrigeration Systems [M.S. Thesis], United States: Mechanical Engineering, Solar Energy Laboratory, University of Wisconsin Madison, 1999.

[23] Y. M. Zhuang, "The energy consumption and economical analysis for evaporative condenser compared to shell-tube water-cooling condensers," Refrigeration, vol. 20, pp. 48-51, 2001. 

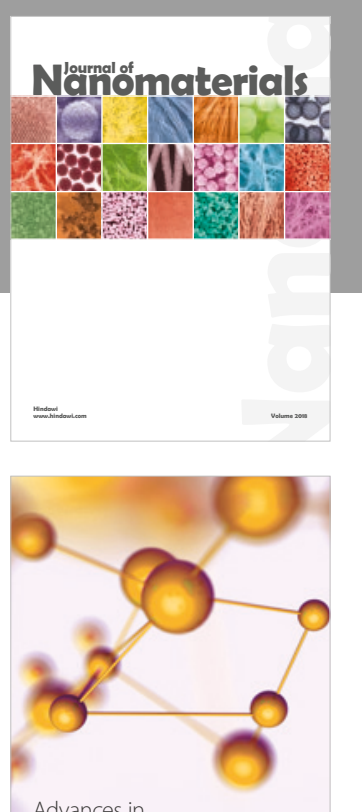

Physical Chemistry
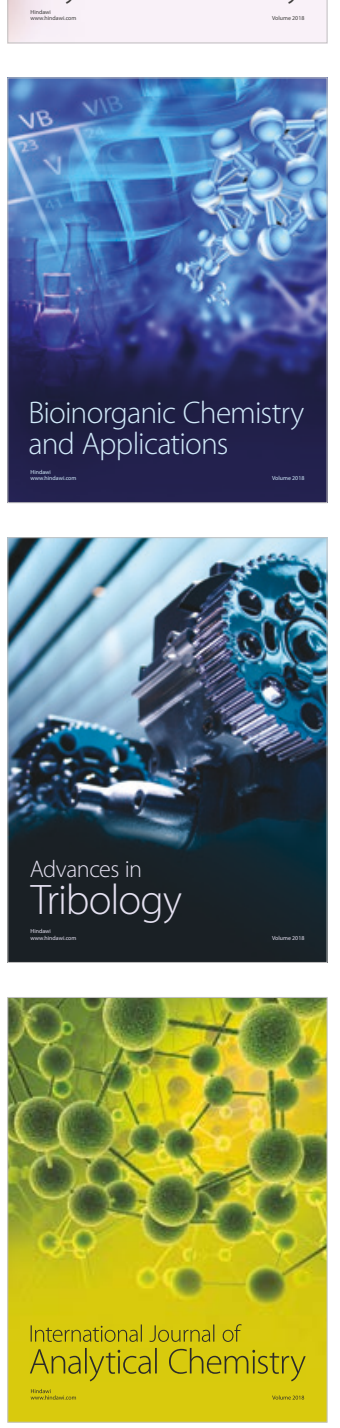

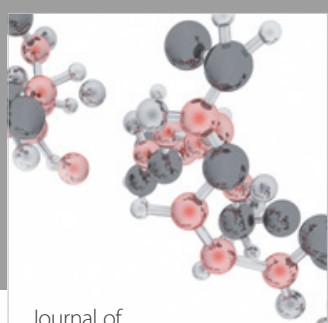

Analytical Methods

in Chemistry

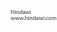

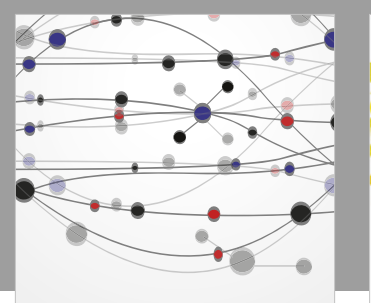

The Scientific World Journal

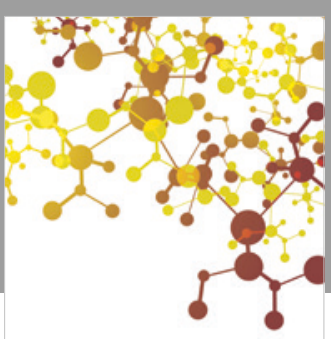

Journal of

Applied Chemistry
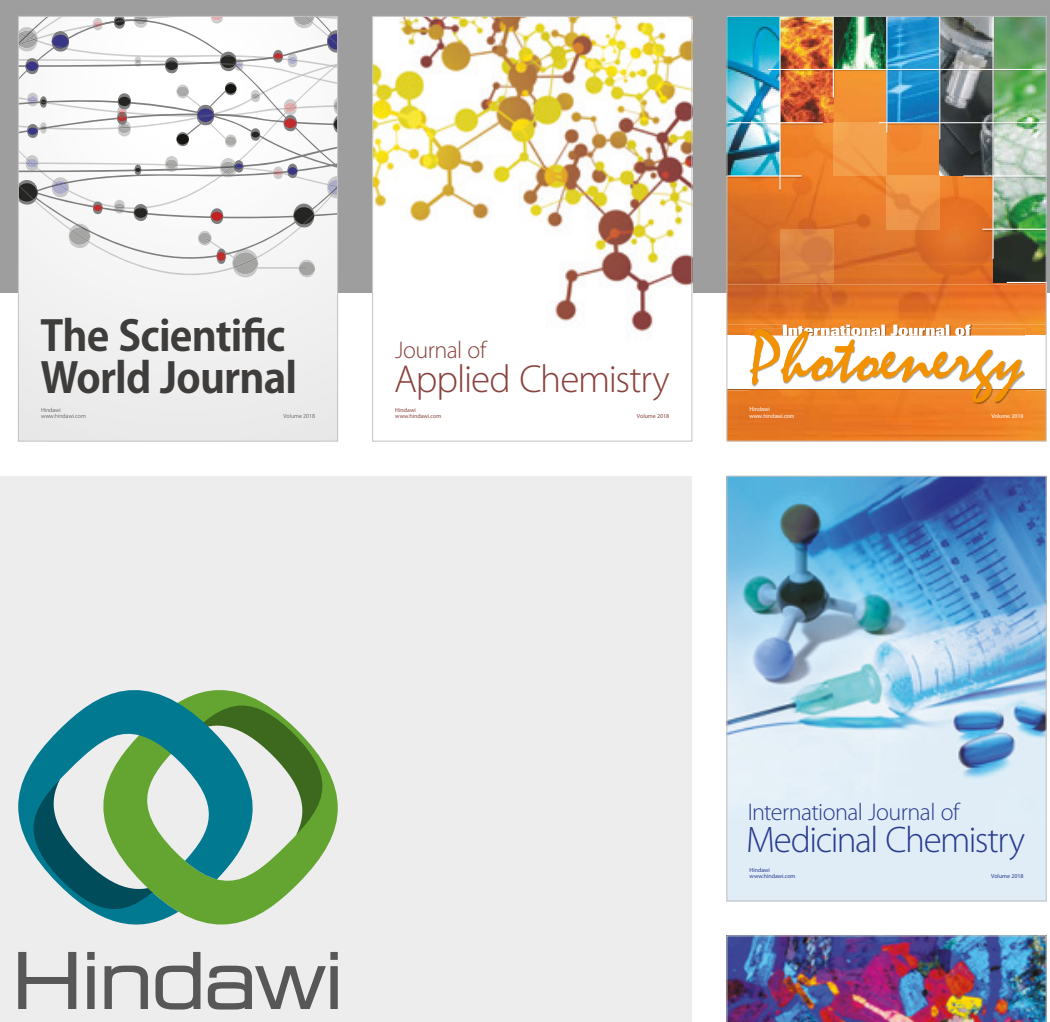

Submit your manuscripts at

www.hindawi.com
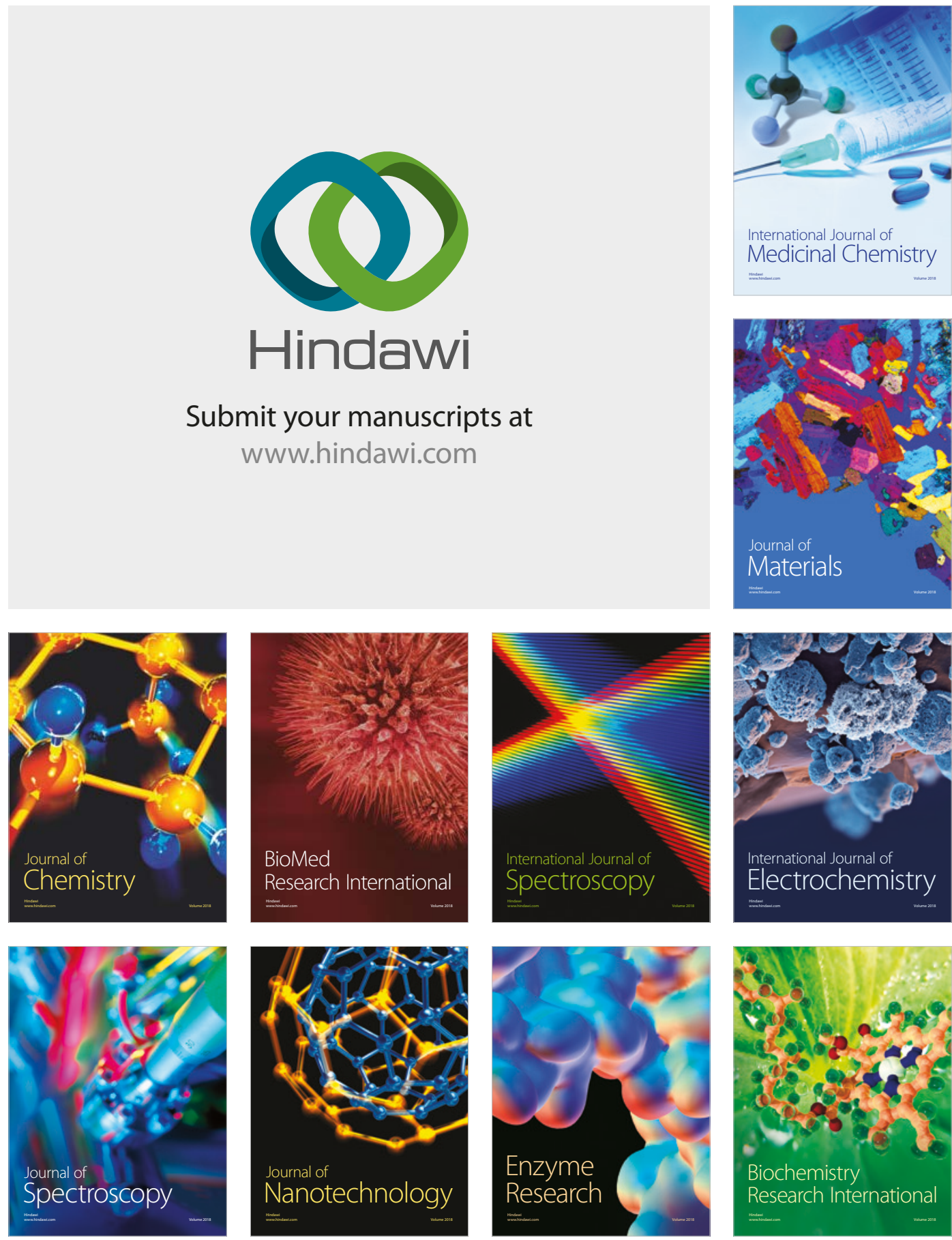
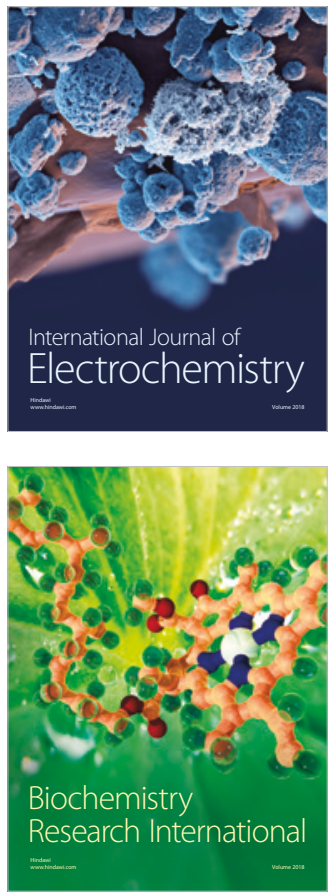